\title{
State transitions revisited-a buffering system for dynamic low light acclimation of Arabidopsis
}

\author{
Mikko Tikkanen · Mirva Piippo $\cdot$ Marjaana Suorsa $\cdot$ Sari Sirpiö · \\ Paula Mulo - Julia Vainonen - Alexander V. Vener - Yagut Allahverdiyeva • \\ Eva-Mari Aro
}

Published online: 6 October 2006

(C) Springer Science+Business Media B.V. 2006

\section{Erratum to: Plant Mol Biol \\ DOI 10.1007/s11103-006-9044-8}

Due to an unfortunate misunderstanding, the given names and surnames of all authors have been interchanged in the official publication. The correct authors' names are listed above and below.

The online version of the original article can be found at http://dx.doi.org/10.1007/s11103-006-9044-8

M. Tikkanen $\cdot$ M. Piippo $\cdot$ M. Suorsa $\cdot$ S. Sirpiö $\cdot$

P. Mulo · J. Vainonen · A. V. Vener ·

Y. Allahverdiyeva · E.-M. Aro $(\bowtie)$

Plant Physiology and Molecular Biology, Department

of Biology, University of Turku, FIN-20014

Turku, Finland

e-mail: evaaro@utu.fi

A. V. Vener

Division of Cell Biology, Linkoping University,

SE-581 85 Linkoping, Sweden 